\title{
A BMP selection process based on the granulometry of runoff solids in a separate urban catchment
}

\author{
José Anta*, Enrique Peña, Joaquín Suárez and Juan Cagiao \\ Civil Engineering School, University of A Coruña, Campus de Elviña s/n, 15071 A Coruña, Spain
}

\begin{abstract}
This article presents the methodology and results of the field survey carried out to characterise the pollution associated with the stormwater runoff from an urban catchment in Galicia (Spain). Various instruments were installed in the control section of this catchment measuring some 55 ha and located in the separate sewer system outlet, to obtain samples associated with stormwater events. In particular, precipitation and flow were recorded, in addition to the pollution associated with such flows. On the basis of this information it was possible to determine a series of pollution parameters (solids, $\mathrm{BOD}_{5}, \mathrm{COD}, \mathrm{TOC}$ ) and the most important event parameters (event mean concentration, maximum concentration, mobilised load per net hectare) were calculated. These results were compared with those from other similar catchments. The analysis of the results includes the determination of probability distribution as well as the study of the particle size distribution of the samples during different periods of the event, which thus enabled us to obtain the relationship between the total rainfall and the particle size distribution of each event. Finally, a study of potential best management practices using the process selection diagrams is presented.
\end{abstract}

Keywords: separate urban catchments; runoff pollution; best management practices; suspended solids; particle size distribution

\section{Introduction}

The world's population has become more and more concentrated in cities, which has had a considerable impact on the growing complexity of the infrastructures, especially those related to the management of water (Butler and Davies, 2000). This high concentration has been responsible for land development and an increase in the impervious surface area of the catchments. Some of the most obvious consequences are the greater volume of runoff and velocity of circulating flux, shorter concentration times and shallower volumes during low water periods. The end result is an overall increase in pollution levels (Novotny and Olem, 1994).

In separate sewage systems, such as the one analysed in this study, the pollution drawn in by runoff waters is the result of both the activities that take place on the surface of the catchments and the re-suspension of sediments within the network.

Studies on the characterisation of pollution in urban runoff have increased significantly in number in recent years. From the first environmental analyses (Sartor and Boyd, 1972, USEPA, 1983), up to the most recent studies (i.e. Taebi and Droste, 2004 and Chebbo and Gromaire, 2004), the general consensus is that the main sources of runoff pollution are sediments accumulated on the street surface and conduit inverts, traffic emissions and chemical substances used to melt ice. These studies also show that most of the pollutants are associated with the finest fractions of the sediments which are the ones most difficult to eliminate by using sedimentation techniques.

Another field where a significant amount of scientific research has been carried out over the past few years is the

* To whom all correspondence should be addressed.

证 +34981 100700 ext 5462; fax: +34 981167170 ;

e-mail: ianta@udc.es

Received 13 January 2006; accepted in revised form 7 April 2006 characterisation and transport of sediments in sewer networks (Crabtree, 1989, Ackers et al., 1996, Ashley et al., 2003, Butler et al., 2003, Ota and Nalluri, 2003). In the case of stormwater sewer systems the sediments found can be classified into two types: stormwater solids and grit material. Stormwater solids, consisting generally of one-fourth organic matter, are transported in suspension, and the characteristic values quoted in the literature vary widely. Thus, the average relative density of the sediment is approximately 2.4 , with $90 \%$ of the particles being smaller than $100 \mu \mathrm{m}$ in size.

Grit sediment constitutes the largest part of the sediments found to be deposited in the sewer networks. These sediments are usually transported along the bed. Although differentiating stormwater sediments is complicated, they are usually defined as the inorganic fraction greater than $150 \mu \mathrm{m}$ with specific density of around 2.7 (Ackers et al., 1996).

The main objective of this study is the characterisation and analysis of the pollution generated by solids in a separate urban catchment outfall during wet periods. For this purpose, a control section was implemented in the catchment outlet, where continuous values of flow and pollution were recorded. Precipitation was obtained using a rain gauge located near the control section, and the volumes and discharges were measured using a flow meter

The results were analysed using various procedures. On the one hand, significant parameters for each of the events were calculated, i.e., average, maximum and minimum values of rainfall and volume. Moreover, in the pollution study, the variability of pollutants in events may be very high. Therefore, some studies (USEPA, 1983) propose an approach that would work with total flow-weighted concentrations to obtain an "event mean concentration" (EMC):

$$
\text { EMC }=\frac{\text { Mass }}{\text { Volume }}=\frac{\sum_{i=1}^{\mathrm{N}} \bar{Q}_{i} \bar{C}_{i} \Delta t_{i}}{\sum_{i=1}^{\mathrm{N}} \bar{Q}_{i} \Delta t_{i}}
$$


where:

$N$ is the number of samples

$\bar{Q}_{i}$ is the average runoff flow rate

$\bar{C}_{i}^{i}$ is the average runoff pollutant concentration

$\Delta t$ is the time interval.

Furthermore, a statistical analysis was carried out with linear regressions and adjustments of probability functions, supplying additional information on expected trends and values for a stormwater event.

Also conducted was a particle analysis of the samples collected, relating the particle size distribution of the flow. The entire battery of sample analyses and the characteristic parameters are data that are essential to the definition of the best management practices for the runoff waters of this urban catchment.

\section{Material and methods}

\section{Description of the urban catchment}

The catchment analysed in this study is part of the drainage system of the city of Santiago de Compostela, capital of the Regional Community of Galicia (Spain), which has a population of around 100000 inhabitants.

The catchment under study, called Fontiñas, is an area which was urbanised some 15 years ago, and consists largely of a residential and commercial area with a low-to-medium level of activity. The catchment has a separate sewage system and an approximate area of some 55 ha, $70 \%$ of which is impervious (38.5 net-ha). It has an average runoff coefficient of approximately 0.65 , a steep slope-roughly $6 \%$, producing hydrographs with high peaks in the control section and a concentration time of around $25 \mathrm{~min}$ (Suárez et al., 2001). With regards to the typology of the main surfaces, the roofs are tiled and the streets have bituminous surfaces, often interspersed with strips of grass.

\section{Description of the control section}

The control section was situated at the outlet of the drain network (see Fig. 1). A small structure was built here to store the different instruments used in the characterisation of the hydrology and associated pollution.

Rainfall was recorded with an ARG100 aerodynamic rain gauge located near the control section. The depth of the water surface was measured with the ultrasonic sensor of a Sigma 950 velocity flow meter, with $3 \mathrm{~mm}$ accuracy. The depth sensor was complemented with a Doppler velocity sensor, having a mean resolution of $0.3 \mathrm{~cm} / \mathrm{s}$ and $2 \%$ accuracy.

Pollution was continuously recorded at the control section with a multi-parametrical YSI 9020 probe, which measured the turbidity, conductivity and temperature of the flow every $5 \mathrm{~min}$ (Anta, 2004). The sampling period was from May to October 2003. An automatic Sigma 900 sample-taker was placed in the control section to characterise the pollution associated with stormwater events. This instrument is equipped with a container that holds 24 plastic bottles, on top of which is a distributor arm that swings back and forth, filling them every $5 \mathrm{~min}$. The results from the previous survey in the same catchment were used to compare these results with dry weather periods (Cagiao, 2002).

In this study pollution related to stormwater events was analysed in detail. It is important to point out that Santiago de Compostela is one of the cities in Spain receiving a high rainfall with a mean annual precipitation of $1886 \mathrm{~mm}$, during the period

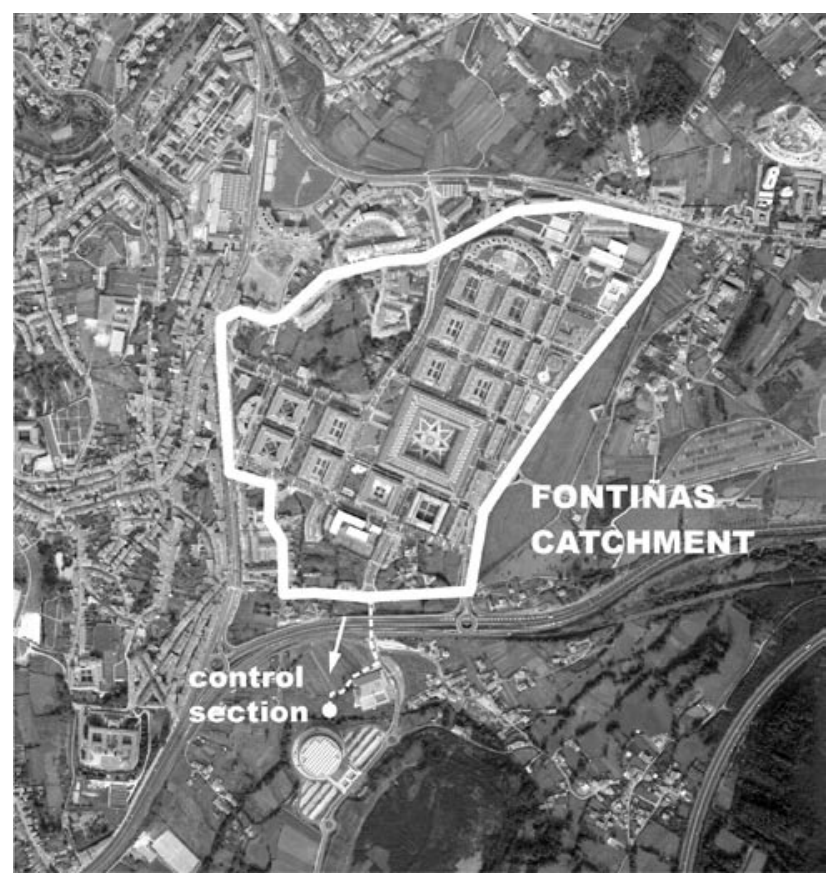

Figure 1

Aerial photograph of the Fontiñas urban catchment

from 1971 to 2000 , and a total of 141 rain-days a year. For this study 14 stormwater events were sampled.

\section{Water quality analysis}

The samples collected were analysed at the Environmental Sanitary Engineering Laboratory of the Civil Engineering School at the University of A Coruña according to standard procedures as in Standard Methods (1998). A large number of pollution parameters were analysed: $\mathrm{pH}$, turbidity (NTU), conductivity $(\mathrm{EC}, \mu \mathrm{S} / \mathrm{cm})$, biochemical oxygen demand $\left(\mathrm{BOD}_{5}, \mathrm{mg} \mathrm{O}_{2} / \ell\right)$, chemical oxygen demand $\left(\mathrm{COD}, \mathrm{mg} \mathrm{O}_{2} / \ell\right)$, total organic carbon (TOC, $\mathrm{mg} / \ell$ ) total solids (TS, $\mathrm{mg} / \ell$ ), total dissolved solids (TDS, $\mathrm{mg} / \ell$ ), total suspended solids (TSS, $\mathrm{mg} / \ell$ ), total volatile solids (TVS, $\mathrm{mg} / \ell$ ), total fixed solids (TFS, $\mathrm{mg} / \ell$ ), fixed dissolved solids (FDS, $\mathrm{mg} / \ell$ ), volatile dissolved solids (VDS, $\mathrm{mg} / \ell$ ), fixed suspended solids (FSS, $\mathrm{mg} / \ell$ ) and volatile suspended solids

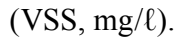

The particle size distribution of the samples taken from the stormwater events was carried out using a COULTER LS-120 laser particle analyser. This instrument deduces the size and proportions of the particles from the liquid sample by calculating the distribution of the intensity of the laser light diffracted by the sample over 92 transducers situated inside the device. This analysis technique allowed us to obtain the percentages in volume, specific surface and number of particles in different particle size intervals of between 0.375 and $2000 \mu \mathrm{m}$.

\section{Process selection diagrams}

A study of the sedimentation capacity using some of the samples was carried out. This analysis is based on two variables used to evaluate the technologies available to eliminate the finer fraction from the suspended solids (SS). The problem with this SS fraction is related to its affinity for other organic pollutants or heavy metals and to its lower settleability. The parameters used in this methodology are the total number of particles per aqueous volume across the entire gradation $\left(N_{t}\right)$ and the number- 
volume mean size $\left(l_{n p}\right)$. The number-volume mean size (Cristina et al., 2002; Cristina and Sansalone, 2003) can be calculated from the particle count originating from each particle size distribution.

$$
I_{n v}=\frac{\sum_{i} N_{i} \cdot l_{i}^{3}}{\sum_{i} N_{i}}=\frac{\sum_{i} N_{i} \cdot l_{i}^{3}}{N_{t}}
$$

where:

$l_{i}$ is the representative diameter of interval $-i$ $\stackrel{i}{N}_{i}$ is the number of particles in particle size interval $-i$

$N_{t}$ is the total number of particles.

To be able to select the best management practice, it is necessary to analyse the settleability of the samples and determine the fall velocity $\left(V_{s}\right)$ using Stoke's law, as well as the hydraulic retention time (HRT). The minimum diameter of the particles that can be settled may be estimated by equating the HRT to the depth of the sedimentation basin divided by the calculated fall velocity.

\section{Results and discussion}

\section{Hydraulics and pollution characterisation}

This section presents the most important results of the analysis of pollution associated with the runoff from this separate catchment in the 14 stormwater events studied.

Summarised in Table 1 are the total depth and average and maximum intensity of the rainfall as well as the maximum, average and minimum values of the flow and volume in the 14 rain events analysed.

The results show that there is a certain base flow during dry periods, whose origin could be associated with infiltration, sources, springs, or possible illegal connections to the network. As can be seen in Table 1, the maximum flow rate recorded in the Fontiñas catchment during the events collected was $451 \mathrm{l} / \mathrm{s}$, a value some 12 times higher than the average base flow during dry periods.

Table 2 gives the maximum values of the concentration of various pollutants collected by the automatic sampler. The values obtained in the tests carried out clearly show that the pollution contributed by the runoff is found in low concentrations. The volume of polluted water can, however, generate short- and long-range impact problems in aquatic systems by exceeding the critical load (problems related to the heavy demand for dissolved oxygen owing to the dumping of organic matter and/or ammoniacal nitrogen, or other problems associated with high concentrations of solids) and the appearance of bio-accumulation problems (basically related to heavy metals in dissolved form).

A parameter commonly used to characterise pollution during a stormwater event is the event mean concentration (EMC, see Table 3). The relationship between the average value of TSS event mean concentrations and the average daily TSS concentration in dry periods is approximately 10:1. The COD relationship is smaller, close to $2.4: 1$, a value which is similar to the relationship obtained with the TOC, 2:1.

In Table 4 pollution is compared by means of the EMC obtained in the Fontiñas catchment with those obtained in other separate catchments. The mobilised load of pollutants towards
TABLE 1

ummary of the hydraulic parameters in the stormwater events analysed

\begin{tabular}{|c|c|c|c|c|c|c|}
\hline $\begin{array}{c}\text { Total } \\
\text { depth } \\
(\mathbf{m m})\end{array}$ & \multicolumn{2}{|c|}{$\begin{array}{c}\text { Intensity } \\
(\mathbf{m m} / \mathbf{h})\end{array}$} & \multicolumn{3}{|c|}{ Flow $\left.\mathbf{( m}^{3} / \mathbf{s}\right)$} & \multirow{2}{*}{$\begin{array}{c}\text { Volume } \\
\left(\mathbf{m}^{3}\right)\end{array}$} \\
\cline { 2 - 6 } & Max & Mean & Max & Mean & Min & \\
\hline 2.7 & 2.9 & 4.8 & 0.136 & 0.076 & 0.035 & 273 \\
\hline 5.6 & 2.4 & 3.6 & 0.246 & 0.161 & 0.051 & 1534 \\
\hline 1.1 & 1.1 & 1.2 & 0.088 & 0.057 & 0.037 & 230 \\
\hline 2.1 & 2.1 & 3.6 & 0.174 & 0.117 & 0.040 & 507 \\
\hline 2.6 & 2.4 & 3.6 & 0.233 & 0.114 & 0.028 & 553 \\
\hline 0.9 & 0.8 & 1.2 & 0.273 & 0.155 & 0.037 & 464 \\
\hline--- & --- & --- & 0.157 & 0.112 & 0.022 & 234 \\
\hline--- & --- & --- & 0.156 & 0.082 & 0.035 & 532 \\
\hline 3.8 & 1.1 & 4.8 & 0.294 & 0.202 & 0.061 & 1402 \\
\hline 0.6 & 2.4 & 2.4 & 0.115 & 0.050 & 0.021 & 179 \\
\hline 2.8 & 0.9 & 9.6 & 0.187 & 0.081 & 0.032 & 400 \\
\hline 4.0 & 2.7 & 9.6 & 0.451 & 0.224 & 0.054 & 1038 \\
\hline 2.6 & 1.7 & 7.2 & 0.203 & 0.112 & 0.037 & 637 \\
\hline 3.8 & 2.7 & 4.0 & 0.386 & 0.138 & 0.029 & 696 \\
\hline 2.7 & 1.9 & 4.6 & 0.221 & 0.120 & 0.037 & 620 \\
\hline 1.5 & & & & & & \\
\hline & & 2.8 & 0.103 & 0.052 & 0.011 & 424 \\
\hline
\end{tabular}

TABLE 2

Maximum concentrations of the pollutants in the stormwater events analysed

\begin{tabular}{|l|c|c|c|c|c|c|}
\hline $\begin{array}{l}\text { Rain } \\
\text { Event }\end{array}$ & $\begin{array}{c}\text { TSS } \\
(\mathbf{m g} / \mathbf{l})\end{array}$ & $\begin{array}{c}\text { TDS } \\
(\mathbf{m g} / \mathbf{l})\end{array}$ & $\begin{array}{c}\text { TS } \\
(\mathbf{m g} / \mathbf{l})\end{array}$ & $\begin{array}{c}\text { COD } \\
(\mathbf{m g} / \mathbf{l})\end{array}$ & $\begin{array}{c}\text { BOD } \\
(\mathbf{m g} / \mathbf{l})\end{array}$ & $\begin{array}{c}\text { TOC } \\
(\mathbf{m g} / \mathbf{l})\end{array}$ \\
\hline 01 & 392 & 290 & 628 & --- & --- & 8 \\
\hline 02 & 656 & 334 & 990 & 295 & --- & 22 \\
\hline 03 & 634 & 254 & 864 & --- & --- & 36 \\
\hline 04 & 1060 & 198 & 1128 & --- & --- & 6 \\
\hline 05 & 3526 & 216 & 3702 & --- & --- & 20 \\
\hline 06 & 84 & 161 & 245 & --- & --- & 8 \\
\hline 07 & 392 & 140 & 507 & --- & --- & 9 \\
\hline 08 & 94 & 121 & 211 & --- & --- & 4 \\
\hline 09 & 156 & 206 & 362 & 92 & --- & --- \\
\hline 10 & 656 & 552 & 1208 & 187 & 80 & --- \\
\hline 11 & 875 & 245 & 1120 & 380 & 205 & --- \\
\hline 12 & 316 & 300 & 474 & 111 & --- & --- \\
\hline 13 & 1062 & 240 & 1214 & 213 & 100 & --- \\
\hline 14 & 1307 & 851 & 1456 & 208 & 65 & --- \\
\hline $\begin{array}{l}\text { Mean } \\
\text { value }\end{array}$ & 801 & 293 & 1008 & 212 & 113 & 14 \\
\hline $\begin{array}{l}\text { Standard } \\
\text { deviation }\end{array}$ & 872 & 192 & 873 & 100 & 63 & 11 \\
\hline
\end{tabular}

the Sar River during stormwater events is of the same magnitude as that of other catchments with similar characteristics reported in the literature. The selected metal results for this catchment come from earlier studies (Cagiao, 2002), and were not analysed in this study.

Another important parameter is the mobilised load per net hectare within the catchment ( $\mathrm{kg} /$ net-ha).This value gives information about the pollution that is being deposited in the catchment and in the collectors, as well as their capacity to mobilise this pollution in a sufficiently long and powerful event (Table 5). 


\begin{tabular}{|c|c|c|c|c|c|c|}
\hline \multicolumn{7}{|c|}{$\begin{array}{c}\text { TABLE } 3 \\
\text { EMC of the pollutants in the stormwater events } \\
\text { analysed }\end{array}$} \\
\hline Rain Event & $\begin{array}{c}\text { TSS } \\
(\mathrm{mg} / \mathrm{\ell})\end{array}$ & $\begin{array}{c}\text { TDS } \\
(\mathrm{mg} / \mathrm{\ell})\end{array}$ & $\begin{array}{c}\text { TS } \\
(\mathrm{mg} / \mathrm{\ell})\end{array}$ & $\begin{array}{c}\text { COD } \\
(\mathrm{mg} / \mathrm{l})\end{array}$ & $\begin{array}{c}\mathrm{BOD}_{5} \\
(\mathrm{mg} / \mathrm{\ell})\end{array}$ & $\begin{array}{c}\text { TOC } \\
\text { (mg/e) }\end{array}$ \\
\hline 01 & 96 & 192 & 288 & --- & --- & 6 \\
\hline 02 & 190 & 105 & 295 & 79 & --- & 9 \\
\hline 03 & 324 & 211 & 535 & --- & --- & 22 \\
\hline 04 & 385 & 81 & 465 & --- & --- & 5 \\
\hline 05 & 590 & 131 & 721 & --- & --- & 10 \\
\hline 06 & 64 & 89 & 153 & --- & --- & 5 \\
\hline 07 & 219 & 93 & 312 & --- & --- & 7 \\
\hline 08 & 50 & 70 & 120 & --- & --- & 3 \\
\hline 09 & 50 & 72 & 122 & 25 & --- & --- \\
\hline 10 & 264 & 196 & 459 & 140 & 49 & --- \\
\hline 11 & 278 & 164 & 442 & 180 & 94 & --- \\
\hline 12 & 117 & 93 & 205 & 54 & --- & --- \\
\hline 13 & 212 & 96 & 308 & 88 & 34 & --- \\
\hline 14 & 230 & 223 & 453 & 58 & 21 & --- \\
\hline Mean value & 219 & 130 & 348 & 89 & 40 & 8 \\
\hline $\begin{array}{l}\text { Standard } \\
\text { deviation }\end{array}$ & 149 & 55 & 173 & 53 & 35 & 6 \\
\hline $\begin{array}{l}\text { Mean value } \\
\text { (dry period) }\end{array}$ & 22 & --- & --- & 37 & --- & 4 \\
\hline
\end{tabular}

An analysis of the mobilisation of volatile SS fractions during the events makes it possible to study the biodegradability of the runoff. In fact, by analysing the relationship that exists between the volatile SS and the organic matter, through mean values, the suitability of potential methods of classic biological treatment can be estimated.

In Table 6 the most important average relationship between the different fractions of solids is presented. The results show that approximately $58 \%$ of the mobilised solids in all the events are TSS. Moreover, the content in organic matter, represented by the volatile fraction of the solids, is around $28 \%$. This fraction is composed of approximately $54 \%$ of suspended material and $46 \%$ of dissolved material. It is also interesting to note that the mobilised volatile fraction is nearly constant, showing $27 \%$ of the suspended fraction and $30 \%$ of the dissolved fraction.

Another commonly used approach to estimate the biodegradability of the waters is based on the relationship between $\mathrm{COD}$ and $\mathrm{BOD}_{5}$. The relationship between these two variables (3.24) is higher compared to the typical values of domestic sewage (2 to 2.5). However, if the mean value obtained in Fontiñas is compared with other separate networks, which exhibit values generally ranging between 4 and 6 , the results show that the presence of inorganic matter in the runoff water in this catchment is somewhat low. Finally, from these two analyses it can be concluded that the runoff of the catchment studied is not appropriate for treatment systems based on classic biological processes.

\begin{tabular}{|c|c|c|c|c|c|}
\hline \multicolumn{6}{|c|}{$\begin{array}{c}\text { TABLE } 4 \\
\text { Characteristics of the pollution in urban runoff. Ranges and mean values in } \\
\text { parenthesis }\end{array}$} \\
\hline Pollutant & Present study & $\begin{array}{l}\text { USEPA } \\
(1983)\end{array}$ & Ellis (1989) & $\begin{array}{l}\text { Metcalf and } \\
\text { Eddy (1991) }\end{array}$ & $\begin{array}{l}\text { Novotny and } \\
\text { Olem (1994) }\end{array}$ \\
\hline 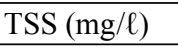 & $50-590(219)$ & $(100)$ & $21-2582(190)$ & $67-101$ & $3-11000(650)$ \\
\hline $\mathrm{COD}(\mathrm{mg} / \ell)$ & $26-180(89)$ & $(65)$ & $20-365(85)$ & $40-73$ & $\begin{array}{ll}--- \\
\end{array}$ \\
\hline $\mathrm{BOD}_{5}(\mathrm{mg} / \ell)$ & $22-95(50)$ & (9) & $7-22(11)$ & $8-10$ & $10-250(30)$ \\
\hline $\mathrm{Pb}(\mu \mathrm{g} / \ell)$ & $13-280(58)$ & $(0.14)$ & $10-3100(210)$ & $27-330$ & $30-3100(300)$ \\
\hline $\mathrm{Zn}(\mu \mathrm{g} / \ell)$ & $136-432(225)$ & $(0.16)$ & $10-3680(300)$ & $135-226$ & $\begin{array}{ll}--- \\
\end{array}$ \\
\hline $\mathrm{Cu}(\mu \mathrm{g} / \ell)$ & $35-159(79)$ & (43) & ---- & ---- & ---- \\
\hline
\end{tabular}

\begin{tabular}{|l|c|c|c|c|c|c|c|c|}
\hline \multicolumn{9}{|c|}{ TABLE 5 } \\
\hline $\begin{array}{l}\text { Rain } \\
\text { Event }\end{array}$ & $\begin{array}{c}\text { TSS (kg/ } \\
\text { net ha) }\end{array}$ & $\begin{array}{c}\text { VSS (kg/ } \\
\text { net ha) }\end{array}$ & $\begin{array}{c}\text { TDS (kg/ } \\
\text { net ha) }\end{array}$ & $\begin{array}{c}\text { VDS (kg/ } \\
\text { net ha) }\end{array}$ & $\begin{array}{c}\text { TS (kg/ } \\
\text { net ha) }\end{array}$ & $\begin{array}{c}\text { COD (kg/ } \\
\text { net ha) }\end{array}$ & $\begin{array}{c}\text { BOD } \text { (kg/ } \\
\text { net ha) }\end{array}$ & $\begin{array}{c}\text { TOC (kg/ } \\
\text { net ha) }\end{array}$ \\
\hline 01 & 0.69 & --- & 1.38 & --- & 2.07 & --- & --- & 0.04 \\
\hline 02 & 7.67 & --- & 4.22 & --- & 11.89 & 3.19 & --- & 0.35 \\
\hline 03 & 1.96 & --- & 1.28 & --- & 3.24 & --- & --- & 0.13 \\
\hline 04 & 5.13 & --- & 1.08 & --- & 6.21 & --- & --- & 0.06 \\
\hline 05 & 8.58 & --- & 1.90 & --- & 10.49 & --- & --- & 0.15 \\
\hline 06 & 0.78 & --- & 1.09 & --- & 1.86 & --- & --- & 0.06 \\
\hline 07 & 1.35 & --- & 0.58 & --- & 1.93 & --- & --- & 0.04 \\
\hline 08 & 0.70 & --- & 0.97 & --- & 1.68 & --- & --- & 0.04 \\
\hline 09 & 1.85 & 0.39 & 2.66 & 0.92 & 4.50 & 0.94 & --- & --- \\
\hline 10 & 1.24 & 0.39 & 0.92 & 0.32 & 2.16 & 0.66 & 0.23 & --- \\
\hline 11 & 2.92 & 1.05 & 1.72 & 0.49 & 4.64 & 1.89 & 0.99 & --- \\
\hline 12 & 3.19 & 0.78 & 2.54 & 0.78 & 5.60 & 1.47 & --- & --- \\
\hline 13 & 3.54 & 0.85 & 1.60 & 0.60 & 5.14 & 1.46 & 0.56 & --- \\
\hline 14 & 4.22 & 0.93 & 4.07 & 0.68 & 8.29 & 1.06 & 0.39 & --- \\
\hline $\begin{array}{l}\text { Mean } \\
\text { value }\end{array}$ & 3.13 & 0.73 & 1.86 & 0.63 & 4.98 & 1.52 & 0.54 & 0.11 \\
\hline $\begin{array}{l}\text { Standard } \\
\text { deviation }\end{array}$ & 2.53 & 0.28 & 1.14 & 0.21 & 3.29 & 0.84 & 0.32 & 0.11 \\
\hline
\end{tabular}

\section{Statistical analysis of the mobilised pollution}

This section is divided into two levels of analysis. The first corresponds to the analysis of the pollutants during periods of rainfall, using all the recordings obtained through all the samples analysed in the laboratory. On the basis of this analysis behavioural patterns of the different pollutants during the rainfall events are obtained. The $2^{\text {nd }}$ part includes an analysis of three integrated parameters assigned to stormwater events: maximum concentration, EMC and mobilised load. With this analysis it is possible to predict the behaviour of the contamination parameters.

\section{Statistical analysis of the pollutant samples}

Apart from the most obvious relationship validating the experimental methodology, the correlations carried out with all the pollutants shed light on others which provide interesting information. A high correlation was obtained between the turbidity recorded with the multi-parametric probe used in field measure- 


\begin{tabular}{|c|c|c|c|c|c|}
\hline $\begin{array}{r}\text { Average } \\
\text { of } \mathbf{s}\end{array}$ & $\begin{array}{l}\text { relations } \\
\text { olids in tl }\end{array}$ & $\begin{array}{r}\text { TAB } \\
\text { ship betw } \\
\text { he stormv }\end{array}$ & $\begin{array}{l}\text { E } 6 \\
\text { een the } \\
\text { vater eve }\end{array}$ & $\begin{array}{l}\text { different fr } \\
\text { nts analys }\end{array}$ & $\begin{array}{l}\text { ractions } \\
\text { sed }\end{array}$ \\
\hline Rain & & Relations & of solids & fractions & \\
\hline & \begin{tabular}{|c|} 
TSS/TS \\
$(\%)$
\end{tabular} & \begin{tabular}{|c|} 
VSS/TSS \\
(\%)
\end{tabular} & $\begin{array}{c}\text { TDS/TS } \\
(\%)\end{array}$ & \begin{tabular}{|c|} 
VDS/TDS \\
(\%)
\end{tabular} & $\begin{array}{c}\text { TVS/TS } \\
(\%)\end{array}$ \\
\hline 01 & 33.43 & --- & 66.57 & --- & --- \\
\hline 02 & 64.48 & --- & 35.52 & $\begin{array}{l}-- \\
\end{array}$ & --- \\
\hline 03 & 60.62 & --- & 39.38 & --- & --- \\
\hline 04 & 81.84 & --- & 18.16 & --- & --- \\
\hline 05 & 82.66 & --- & 17.34 & --- & --- \\
\hline 06 & 41.69 & --- & 58.31 & --- & --- \\
\hline 07 & 70.05 & --- & 29.95 & --- & $\begin{array}{l}-- \\
\end{array}$ \\
\hline 08 & 41.92 & --- & 58.08 & --- & --- \\
\hline 09 & 41.00 & 21.01 & 59.00 & 34.70 & 29.09 \\
\hline 10 & 57.43 & 31.86 & 42.57 & 34.39 & 32.94 \\
\hline 11 & 62.95 & 35.97 & 37.05 & 28.70 & 33.27 \\
\hline 12 & 57.02 & 24.42 & 45.45 & 30.59 & 27.83 \\
\hline 13 & 68.92 & 24.05 & 31.08 & 37.73 & 28.30 \\
\hline 14 & 50.87 & 22.04 & 49.13 & 16.71 & 19.43 \\
\hline $\begin{array}{l}\text { Mean } \\
\text { value }\end{array}$ & 58.21 & 26.56 & 41.97 & 30.47 & 28.48 \\
\hline $\begin{array}{l}\text { Standard } \\
\text { deviation }\end{array}$ & 15.15 & 5.98 & 15.18 & 7.46 & 5.01 \\
\hline
\end{tabular}

ments, the total solids (TS, $\left.\mathrm{R}^{2}=0.93\right)$, and the TSS $\left(\mathrm{R}^{2}=0.93\right)$. These correlation levels were also found between the turbidity measured in the laboratory and TS and TSS samples (Fig. 2), with coefficients of correlation greater than 0.90 .

The probability distribution functions were fitted using the lognormal function, as recommended in the literature on hydrology and pollution (Butler and Davies, 2000). The Anderson-Darling (A-D) statistic is a measurement of how far the plot points fall from the fitted line in a probability plot. A smaller A-D statistic indicates that the distribution fits the data better (Suárez and Puertas, 2005).

Excellent fits were obtained for the TSS and TDS (see Fig. 3). COD and TOC exhibited good fits while $\mathrm{BOD}_{5}$ showed an acceptable adjustment, with an A-D value of 1.447. The corresponding confidence interval was associated with each curve having a $95 \%$ significance level. This resulted in the two curves that accompany the regression line on both sides

\section{Statistical analysis of the parameters of the stormwater events analysed}

The first analysis corresponds to the linear regressions between the following parameters of the pollutants: maximum concentrations, EMC and mobilised load. A highly significant relationship was found between the TS and the TSS, as was to be expected, as well as between the COD and the VSS, with correlations close to 0.9 (Table 7).

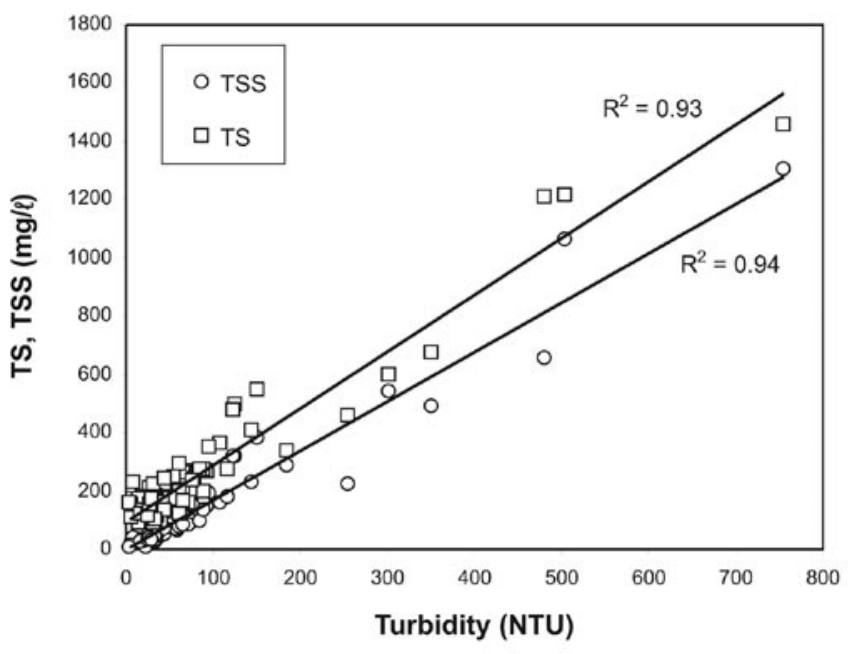

Figure 2

Relationship between the turbidity measured in the laboratory and TS and TSS

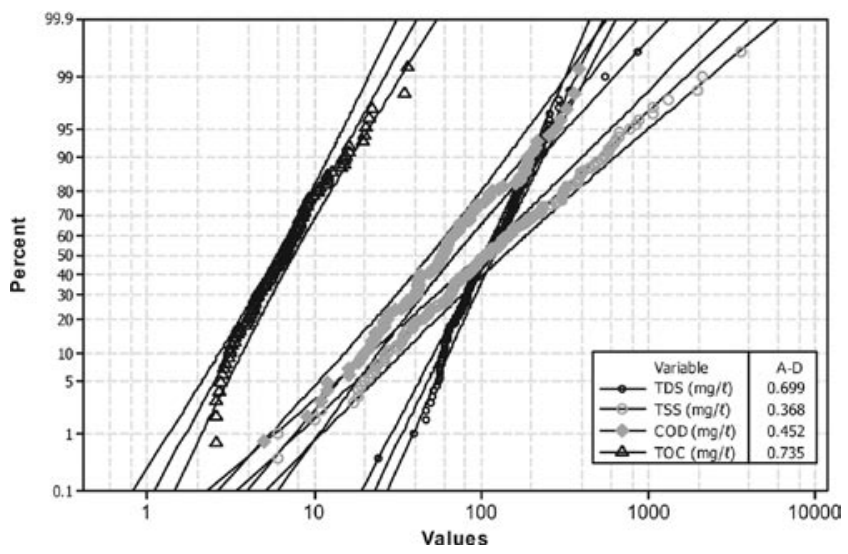

Figure 3

Adjustments of TSS, TDS, COD and TOC with the lognormal distribution

The correlations between the pollutants with the hydrological parameters of the events have also been analysed: antecedent dry period (ADP), precipitation, rainfall intensity, volume of the event and water volume. However, no significant trends were seen within these hydrological parameters.

The most interesting result is related to the analysis of the antecedent dry period. Some recent studies on the rain-to-runoff transformation in urban catchments have questioned whether or not the antecedent dry period is the most influential variable in the wash-off process (Sutherland and Jelen, 2003). Moreover, in other studies on the characterisation of pollution (Chaberneu and Barret, 1998; Deletic and Maksimovic 1998) there is no significant correlation of this parameter with the mobilised load or the EMC of the events. As Fig. 4 shows, this study confirms the independence of this parameter with respect to the pollutant loads in the catchment studied.

\begin{tabular}{|l|c|c|c|c|}
\hline \multicolumn{5}{|c|}{ TABLE 7 } \\
Relationship between the integrated parameters of the pollutants \\
\hline & \multicolumn{2}{|c|}{ COD, VSS } & \multicolumn{2}{c|}{ TS, TSS } \\
\hline Cmax (mg/ $/$ ) & $\mathrm{COD}=1.06 \cdot \mathrm{VSS}+8.70$ & $\mathrm{R}^{2}=0.76$ & $\mathrm{TS}=0.97 \cdot \mathrm{TSS}+10.82$ & $\mathrm{R}^{2}=0.96$ \\
\hline EMC (mg/ $)$ & $\mathrm{COD}=1.67 \cdot \mathrm{VSS}-1.22$ & $\mathrm{R}^{2}=0.94$ & $\mathrm{TS}=1.03 \cdot \mathrm{TSS}+106.50$ & $\mathrm{R}^{2}=0.93$ \\
\hline Mobilized load (kg/net ha) & $\mathrm{COD}=1.32 \cdot \mathrm{VSS}+0.28$ & $\mathrm{R}^{2}=0.65$ & $\mathrm{TS}=1.13 \cdot \mathrm{TSS}+1.15$ & $\mathrm{R}^{2}=0.89$ \\
\hline Mass flux & $\mathrm{COD}=1.19 \cdot \mathrm{VSS}+4.12$ & $\mathrm{R}^{2}=0.76$ & $\mathrm{TS}=0.99 \cdot \mathrm{TSS}+24.02$ & $\mathrm{R}^{2}=0.99$ \\
\hline
\end{tabular}




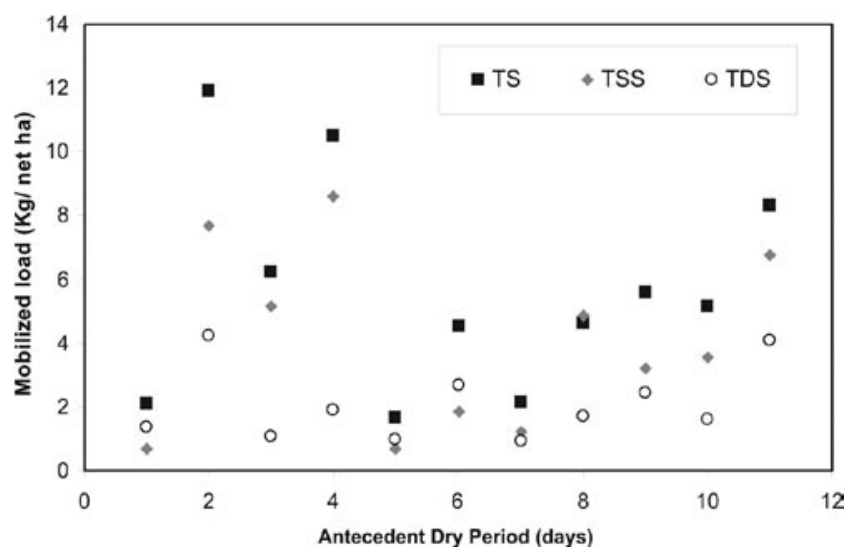

Figure 4

Relationship between the mobilised load and ADP

The analysis of the probability distribution has been carried out for TSS, TDS, TS and COD (Fig. 5) using the maximum concentration and the EMC. Acceptable fits were obtained with A-D values ranging between 1.31 and 1.68.

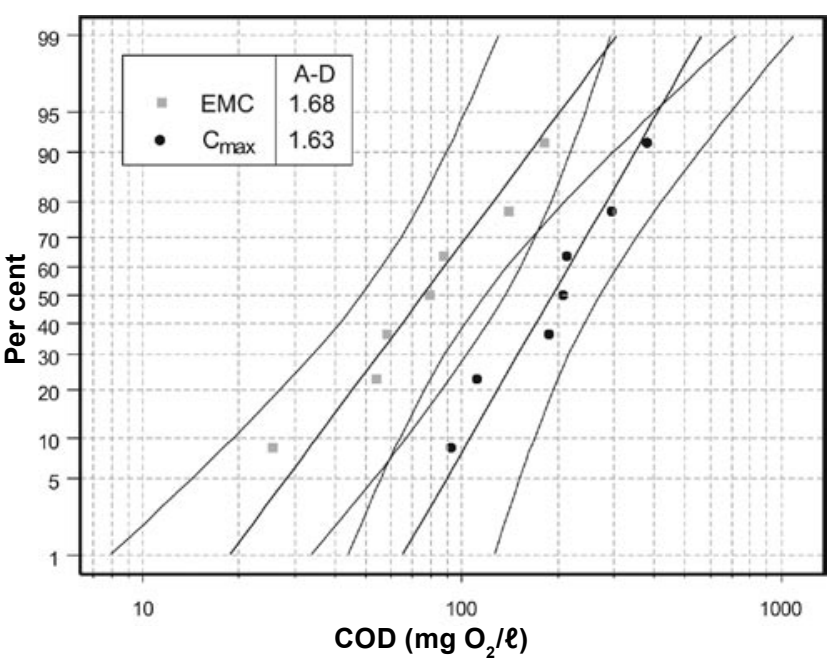

Figure 5

Adjustments of COD maximum concentration and event mean concentration with the lognormal distribution

\begin{tabular}{|c|c|c|c|c|c|c|c|}
\hline \multicolumn{8}{|c|}{$\begin{array}{c}\text { TABLE } 8 \\
\text { Summary of the grain particle size distribution parameters of the sampled events }\end{array}$} \\
\hline \multirow[t]{2}{*}{ Rain Event } & \multirow[t]{2}{*}{ Sample } & \multirow{2}{*}{$\begin{array}{l}\text { TSS } \\
(\mathrm{mg} / \mathrm{l})\end{array}$} & \multicolumn{4}{|c|}{$\%$ size fraction } & \multirow[t]{2}{*}{$d_{50}$} \\
\hline & & & $\begin{array}{l}<63 \\
(\mu \mathrm{m})\end{array}$ & $\begin{array}{c}63-125 \\
(\mu \mathrm{m})\end{array}$ & $\begin{array}{l}125-250 \\
(\mu \mathrm{m})\end{array}$ & $\begin{array}{l}>250 \\
(\mu \mathrm{m})\end{array}$ & \\
\hline \multirow{8}{*}{09} & 1 & 156 & 70 & 17 & 9 & 4 & 36 \\
\hline & 2 & 143 & 74 & 15 & 6 & 5 & 34 \\
\hline & 3 & 113 & 68 & 14 & 7 & 11 & 39 \\
\hline & 4 & 88 & 69 & 16 & 8 & 6 & 39 \\
\hline & 5 & 65 & 74 & 16 & 6 & 4 & 36 \\
\hline & 6 & 54 & 72 & 16 & 7 & 6 & 36 \\
\hline & 12 & 50 & 72 & 14 & 7 & 7 & 36 \\
\hline & 18 & 26 & 42 & 30 & 18 & 11 & 79 \\
\hline \multicolumn{2}{|l|}{ Mean value } & $50 *$ & 68 & 17 & 9 & 7 & 42 \\
\hline \multirow{5}{*}{10} & 1 & 656 & 71 & 16 & 13 & 0 & 25 \\
\hline & 2 & 490 & 69 & 13 & 12 & 6 & 38 \\
\hline & 3 & 228 & 98 & 2 & 0 & 0 & 26 \\
\hline & 7 & 68 & 100 & 0 & 0 & 0 & 15 \\
\hline & 12 & 390 & 100 & 0 & 0 & 0 & 9 \\
\hline \multicolumn{2}{|l|}{ Mean value } & $264 *$ & 88 & 6 & 5 & 1 & 22 \\
\hline \multirow{6}{*}{11} & 1 & 875 & 70 & 14 & 8 & 9 & 38 \\
\hline & 3 & 382 & 71 & 15 & 9 & 6 & 40 \\
\hline & 6 & 97 & 61 & 19 & 11 & 9 & 50 \\
\hline & 10 & 26 & 74 & 15 & 7 & 4 & 34 \\
\hline & 13 & 33 & 68 & 20 & 10 & 2 & 36 \\
\hline & 17 & 11 & 67 & 20 & 10 & 4 & 44 \\
\hline \multicolumn{2}{|l|}{ Mean value } & $278 *$ & 68 & 17 & 9 & 6 & 40 \\
\hline \multirow{7}{*}{13} & 1 & 1062 & 77 & 12 & 6 & 5 & 31 \\
\hline & 2 & 220 & 78 & 11 & 6 & 5 & 30 \\
\hline & 3 & 181 & 76 & 11 & 7 & 7 & 30 \\
\hline & 9 & 74 & 77 & 12 & 6 & 4 & 29 \\
\hline & 10 & 542 & 76 & 12 & 6 & 6 & 31 \\
\hline & 12 & 132 & 69 & 15 & 8 & 8 & 39 \\
\hline & 17 & 74 & 72 & 10 & 6 & 4 & 26 \\
\hline \multicolumn{2}{|l|}{ Mean value } & $212 *$ & 75 & 12 & 6 & 5 & 31 \\
\hline \multicolumn{3}{|c|}{ Mean value of all samples } & 70.3 & 15.3 & 8 & 5.9 & 38 \\
\hline \multicolumn{3}{|c|}{ Standard deviation } & 7.6 & 4.2 & 2.7 & 2.4 & 10.9 \\
\hline
\end{tabular}

Characterisation of particle size distribution

The particle size distribution of the samples from some of the significant events is analysed in this section. This study has allowed us to determine a relationship between the sediment diameter and the flow, for the purpose of establishing the sediment transport capacity.

A total of 26 particle size distribution analyses, distributed in events 09,10 , 11 and 13 , were carried out, with their representative parameters summarised in Table 8 . The column indicating the sample number shows the order in which the samples were collected, with a frequency of 5 min between two consecutive samples. The analysis was centred on the first intervals of the rainfall event, although some samples are included from the final part of the event.

The results show that the mean sediment diameter of the rainfall events is similar, with the exception of Event 10. In this event almost all the sediments belong to a fraction of less than $63 \mu \mathrm{m}$, and the particles of greater than $250 \mu \mathrm{m}$ are not mobilised. In Fig. 6 the relation- 
ship between the mobilisation of the particles and the total volume of the event is represented.

The correlation coefficients for logarithmical adjustment fluctuate between 0.96, for Event 10, and 0.98 for Event 9. These results are especially interesting when compared with other available studies. Previous papers have proposed a linear relationship between the volume of runoff and the particle size distribution of the mobilised sediments under $100 \mu \mathrm{m}$ in the city of Toronto (Heaney et al., 2000). In the case of the Fontiñas catchment, within the group of particles under $200 \mu \mathrm{m}$, the tendency is logarithmic, although in this analysis only the events of less than $4 \mathrm{~mm}$ of rainfall were studied.

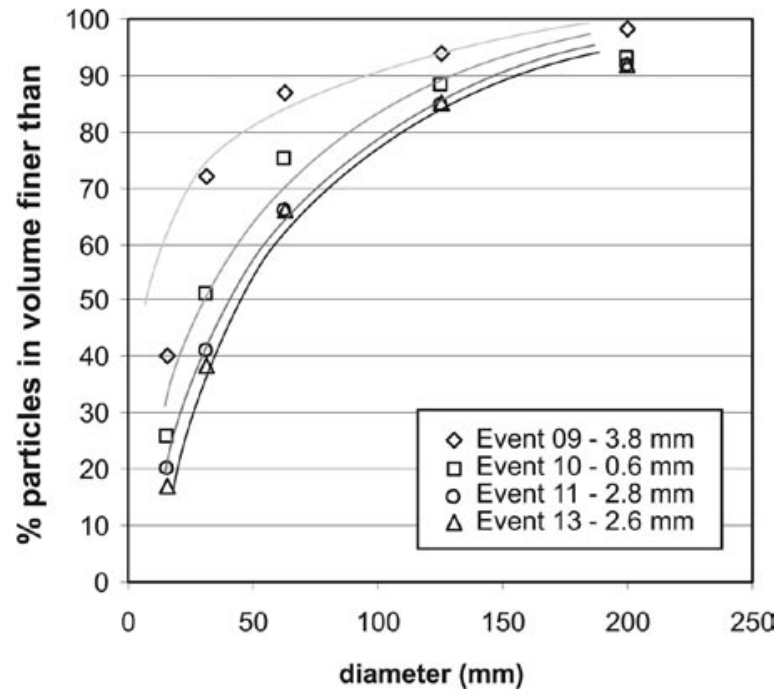

Figure 6

Particle size distribution with different rainfall

TABLE 9

Classification of sediment from the sewer system according to the concentration, mean diameter and average relative density, $\rho_{r}$ (present study and Butler et al., 2003)

\begin{tabular}{|l|l|l|c|c|c|}
\hline \multirow{2}{*}{$\begin{array}{l}\text { Sediment } \\
\text { type }\end{array}$} & Transport & Parameter & \multicolumn{3}{|c|}{ Sediment load } \\
\cline { 4 - 6 } & & & Low & Median & High \\
\hline Stormwater & Suspension & Concentration $(\mathrm{mg} / \ell)$ & 50 & 350 & 1000 \\
& & 20 & 60 & 100 \\
& & $\mathrm{~d}_{50}(\mu \mathrm{m})$ & 1.1 & 2.0 & 2.5 \\
\hline \multirow{2}{*}{ Grit } & $\rho_{\mathrm{r}}$ & 10 & 50 & 200 \\
& \multirow{2}{*}{ Bedload } & Conc. $(\mathrm{mg} / \ell)$ & 300 & 750 & 750 \\
& & $\mathrm{~d}_{50}(\mu \mathrm{m})$ & 2.3 & 2.6 & 2.6 \\
\hline Present & --- & $\rho_{\mathrm{r}}$ & 219 & & \\
study & & $\mathrm{EMC}(\mathrm{mg} / \ell)$ & 38 & & \\
\hline
\end{tabular}

\section{TABLE 10}

Particle size distribution and settling velocity (present study and USEPA, 1986)

\begin{tabular}{|c|c|c|c|c|c|c|}
\hline \multirow[t]{2}{*}{ Group } & \multirow{2}{*}{$\begin{array}{c}\% \\
\text { intervals, } \\
\text { particle } \\
\text { size } \\
\text { distribu- } \\
\text { tion }\end{array}$} & \multirow{2}{*}{$\begin{array}{l}\text { Fontiñas } \\
\text { extra- } \\
\text { polation } \\
(\mu \mathrm{m})\end{array}$} & \multirow{2}{*}{$\begin{array}{c}\text { Settling } \\
\text { velocity } \\
\text { (cm/h), } \\
\text { (USEPA, } \\
\text { 1986) }\end{array}$} & \multicolumn{3}{|c|}{$\begin{array}{l}\text { Settling velocity }(\mathrm{cm} / \mathrm{h}) \\
\text { Stoke's law }\end{array}$} \\
\hline & & & & $\begin{array}{l}\rho_{\mathrm{s}}=1.1 \\
\mathbf{g} / \mathrm{cm}^{3}\end{array}$ & $\begin{array}{c}\rho_{\mathrm{s}}=2 \\
\mathbf{g} / \mathrm{cm}^{3}\end{array}$ & $\begin{array}{c}\rho_{\mathrm{s}}=2.73 \\
\mathbf{g} / \mathrm{cm}^{3}\end{array}$ \\
\hline 1 & $0-20$ & $<10$ & 0.9 & 0.8 & 7.5 & 13.0 \\
\hline 2 & $20-40$ & $10-30$ & 9.1 & 9.8 & 97.6 & 168.9 \\
\hline 3 & $40-60$ & $30-55$ & 45.72 & 43.9 & 439.3 & 759.9 \\
\hline 4 & $60-80$ & $55-100$ & 213.4 & 132.8 & 1327.5 & 2296.6 \\
\hline 5 & $80-100$ & $>100$ & 1981.2 & 707.7 & 7076.9 & 12243.0 \\
\hline
\end{tabular}

In order to characterise the sediment from Fontiñas, the results are shown and grouped in comparison with published information (Table 9). The comparison shows that the samples resemble so-called stormwater sediments with a medium load. As already stated, the rainfall events recorded are not considered to be very energetic. For this reason, no fractions greater than $\mu \mathrm{m}$ were collected, although granular sediments were also found in situ. No characterisation of this type of sediment was made, as the sampler was not able to collect these fractions. On the other hand, these sediments do not require such a detailed characterisation to be able to define potential sedimentation treatment.

The results of the sediment transport capacity of suspended solids in two of the events, separated by particle fractions, are shown in Fig. 7. A comparison of all the events analysed showed similar results, and in each case the highest proportion of particles was observed to be less than $63 \mu \mathrm{m}$. As regards, a smaller number of particles is mobilised for the rest of the fractions. In Event 13 the mobilisation of the particles decreases after the $2^{\text {nd }}$ rainfall peak because most of the available pollution has been washed off previously.

The results of the particle size distribution for the samples collected in Events 10 and 13 are shown in Fig. 8. A comparison of these graphs also provides important information on mobilisation capacity. In Event 10, which has the lowest wash-off energy, the mobilisation of all fractions is less intense and more gradual. In Event 13, all of the fractions begin to overlap after the $2^{\text {nd }}$ or $3^{\text {rd }}$ sample because the energetic capacity is higher. This latter behaviour is similar to the three other events having greater runoff volumes.

\section{Process selection diagrams}

On the basis of the data recorded with the Coulter LS-120 particle analyser, the number of particles in each of the 93 measuring intervals was extracted. In order to process the sediment size, the particle size distribution was limited to a range of between 0.345 and $0.450 \mu \mathrm{m}$ and from 2000 to $250 \mu \mathrm{m}$. The lower limit was changed to $0.45 \mu \mathrm{m}$ given that it corresponds to the pore of the filters used to differentiate the volatile fraction from the suspended fraction. The smallest sizes were counted in the analyses as TDS. The upper limit was reduced to $250 \mu \mathrm{m}$ since larger particles were not expected to be found, as demonstrated in the sections above.

With the number of particles in each interval, and using Eq. (2), the number-volume mean size $\left(1_{n v}\right)$, can be calculated, assuming that the mean diameter of each interval corresponds to the number-volume size.

The application of the process selection diagram methodology (Cristina et al., 2002; Cristina and Sansalone, 2003) to the Fontiñas catchment requires the determination of the density of the SS. In order to obtain this parameter the values of the fall velocity, grouped into five different fractions obtained in prior studies (USEPA, 1986), are shown (Table 10), and the values obtained from the Stoke's law with different densities are presented. 
EVENT 10

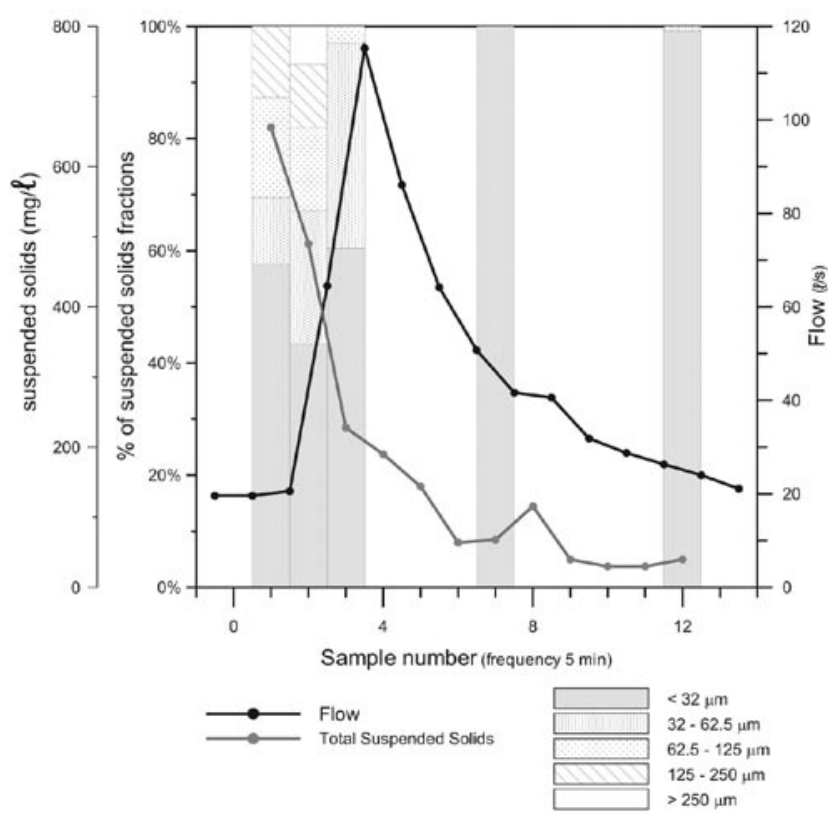

EVENT 13

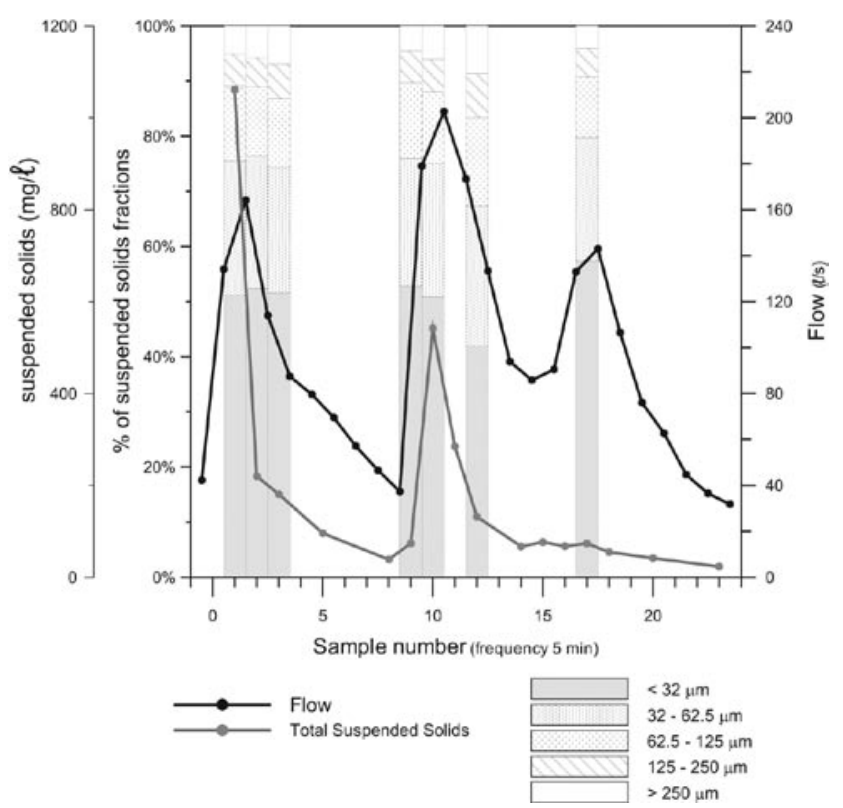

Figure 7

Mobilisation of TSS during Events 10 and 13

After the initial analysis, the settling velocity values resulting from USEPA methodology were found to be similar to those obtained using Stoke's law for a density of $1.1 \mathrm{~g} / \mathrm{cm}^{3}$. As has been mentioned before, during on-site visits the existence of granular sediment was observed around the control section. This would imply that the theoretical value of $1.1 \mathrm{~g} / \mathrm{cm}^{3}$ is lower than the mean value of the mobilised particles.

It is therefore possible to carry out an approach to determine the density of the sediments sampled in Fontiñas using the relationship between the volatile and the mineral SS fractions. On the one hand, approximately $28 \%$ of the organic matter is associated with the suspended solids, giving a density of $1.1 \mathrm{~g} / \mathrm{cm}^{3}$ to this fraction. On the other hand, the density of the mineral
EVENT 10

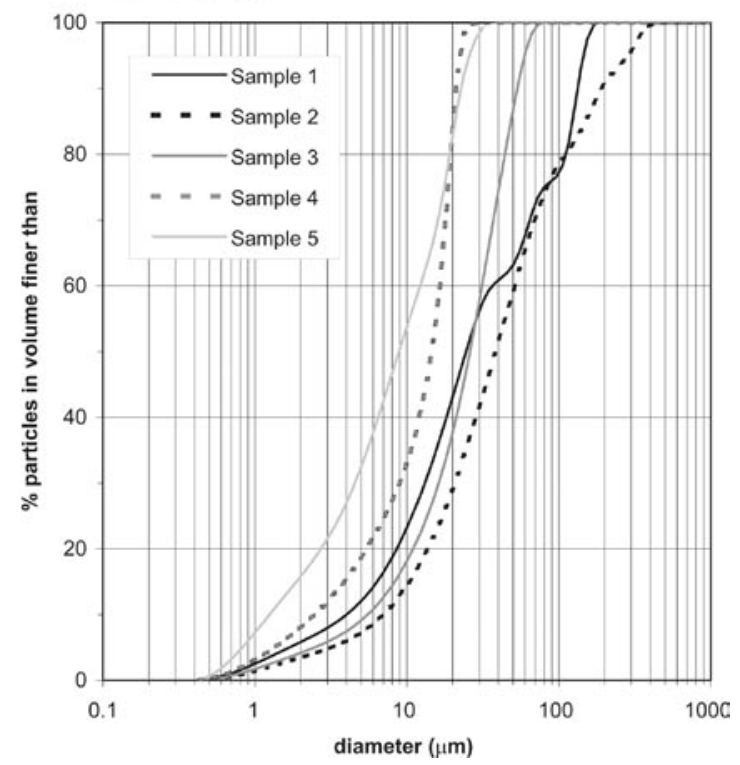

EVENT 13

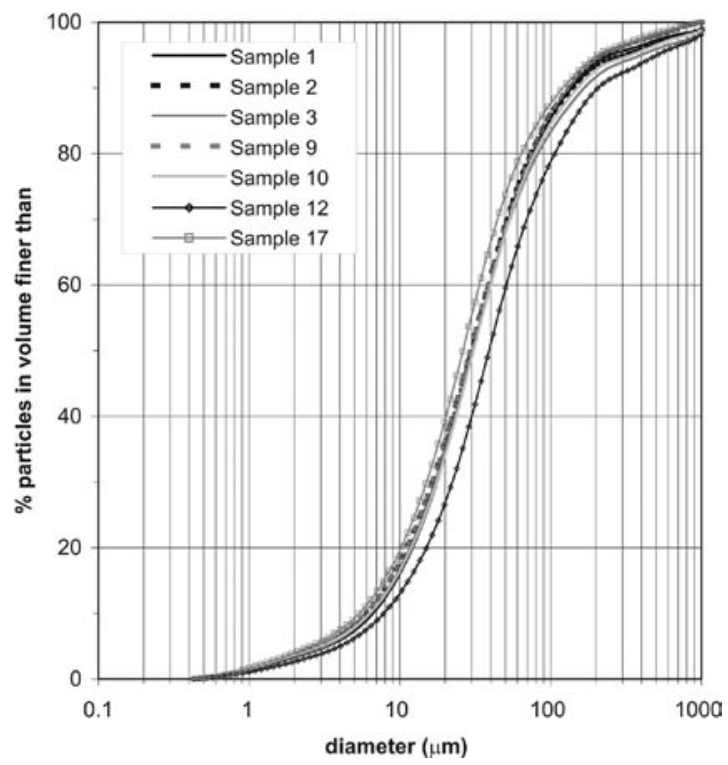

Figure 8

Particle size distribution accumulated in the samples from Events 10 and 13

fraction is around $2.4 \mathrm{~g} / \mathrm{cm}^{3}$. Considering these values we obtained an estimated density of $2.04 \mathrm{~g} / \mathrm{cm}^{3}$.

Finally, the values found for these parameters are presented (Table 11). First, an HRT for the stormwater pond of 1 or $2 \mathrm{~d}$ was assumed, with an average depth of $1.5 \mathrm{~m}$, as recommended in the literature (USEPA, 2004). Based on these values the surface load can be obtained which, matched with the settling velocity $\left(\mathrm{V}_{\mathrm{s}}\right)$, provides the value corresponding to the minimum diameter of the particles $\left(\mathrm{d}_{\mathrm{s}}\right)$ that settle in the pond.

The value of this diameter can be assimilated to the numbervolume mean size $\left(1_{n v}\right)$, determining the settling region in the process selection diagrams. The separation boundaries between the different processes are based on a $90 \%$ particle removal by mass criterion (Cristina et al., 2002). Figures 9 and 10 represent the diagrams $\left(\mathrm{N}_{\mathrm{t}}-1_{\mathrm{nv}}\right)$ for densities of $1.1 \mathrm{~g} / \mathrm{cm}^{3}$ and $2.04 \mathrm{~g} / \mathrm{cm}^{3}$ respectively. 


\begin{tabular}{|c|c|c|c|}
\hline \multicolumn{4}{|c|}{ TABLE 11 } \\
$\begin{array}{c}\text { Surface load and minimum settling } \\
\text { diameters for a stormwater pond with } \\
\text { a mean depth of } \mathbf{1 . 5} \mathbf{~ m}\end{array}$ \\
\hline HRT (hours) & $\mathbf{V}_{\mathbf{s}}$ (m/d) & $\rho_{\mathbf{s}}\left(\mathbf{g} / \mathbf{c m}^{3}\right)$ & $\mathbf{d}_{\mathbf{s}}(\mu \mathbf{m})$ \\
\hline 24 & 1.5 & 2.04 & 5.5 \\
\hline 12 & 3 & 2.04 & 7.8 \\
\hline 24 & 1.5 & 1.1 & 17.9 \\
\hline 12 & 3 & 1.1 & 25.3 \\
\hline
\end{tabular}

The results show that the design of the sedimentation ponds is suitable for the elimination of the fine sediments associated with urban runoff from the catchment analysed, as well as even higher-density sediments. With relatively short retention times, around $1 \mathrm{~d}$, problems may only occur with sediments of a lower density.

These diagrams were based on the assumption that the ponds have a permanent volume of water (wet ponds) in which sedimentation is produced under quiescent conditions. It is obvious that when sedimentation is produced under turbulent conditions, performance is reduced.

\section{Conclusions}

This study presents the characterisation of the pollution from stormwater events in a separate urban catchment, with a surface area of 55 ha, of which $70 \%$ is constructed (38.5 net-ha) and an average slope of $6 \%$. The results show a great variation in all the parameters studied: water flow, event mean concentration, maximum concentrations, mass flux and mobilised load per net hectare.

The pollution associated with the events has been compared with other studies in similar catchments, resulting in similar values. The event mean concentration of suspended solids is 219 $\mathrm{mg} / \ell$, whereas the mean values of COD and BOD $_{5}$ are $89 \mathrm{mg} / \ell$ and $50 \mathrm{mg} / \ell$, respectively. These results are situated in the lower part of the typical pollution range shown in the literature.

The statistical analysis showed that there is a good fit of the different pollutants in the samples analysed to the lognormal function. In the study of the event parameters no significant relationships were found, especially between the antecedent dry period and the mobilised load, in keeping with the findings of other recent analyses.

A detailed study of the particle size distribution mobilised during the different periods of the events was carried out. In the catchment analysed, a logarithmic relationship between the total precipitation and the particle size distribution of each event was obtained. The results allowed us to characterise the material circulating through the network as medium-load stormwater sediments.

Finally, a study of the settleability of the samples by means of the process selection diagrams was carried out, with the total number of particles $\left(\mathrm{N}_{\mathrm{t}}\right)$ and the number-volume mean size $\left(1_{\mathrm{nv}}\right)$. The results of this work have made it possible to select the optimum best management practices for the treatment of the finest sediments $(<250 \mu \mathrm{m})$, and lead to the conclusion that the stormwater pond with an HRT of $1 \mathrm{~d}$ allowed for the elimination of most of the settleable solids found in the runoff of this urban catchment.

\section{Acknowledgements}

The authors are grateful for the support provided by the following institutions:

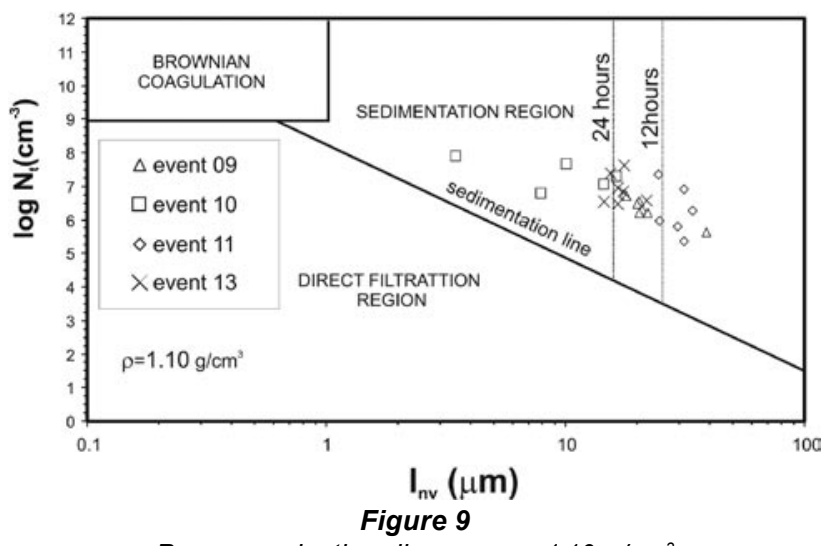

Process selection diagram. $\rho_{s}=1.10 \mathrm{~g} / \mathrm{cm}^{3}$

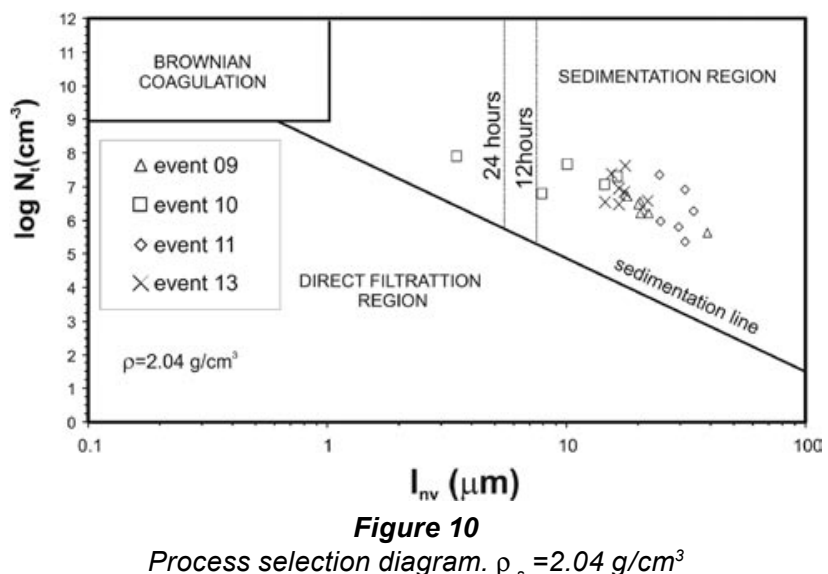

- Ministry of Education and Culture. National Programme for Hydrological Resources. (CICYT) HID99-0310.

- Xunta de Galicia. Galician Plan for Investigation and Development PGIDT-00PXI11803PN.

- Aquagest. The company responsible for the management of sewage in the city of Santiago de Compostela (Galicia, Spain).

\section{References}

ACKERS JC, BUTLER D and MAY WP (1996) Design of Sewers to Control Sediment Problems. CIRIA Report No. R141. CIRIA, London. $181 \mathrm{pp}$.

ANTA J (2004) Estudio de las cargas movilizadas de sólidos por la escorrentía en una cuenca urbana separativa. Análisis de los modelos de acumulación, lavado y arrastre (in Spanish). Unpublished minor thesis, University of A Coruña, Spain.

ASHLEY RM, CRABTREE B, FRASER A and HVITED-JACOBSEN $T$ (2003) European research into sewer sediments and associated pollutants and processes. J. Hydraul. Eng.-ASCE 129 267-265.

BUTLER D and DAVIES JW (2000) Urban Drainage. E\&FN Spon, New York. 512 pp.

BUTLER D, MAY R and ACKERS J (2003) Self-cleansing sewer design based on sediment transport principles. J. Hydraul. Eng.-ASCE 129 276-282.

CAGIAO J (2002) Estudio del funcionamiento hidráulico y de la movilización de la contaminación durante sucesos de lluvia de una cuenca unitaria y una separativa en el noroeste de España (in Spanish). Unpublished Ph.D. thesis, University of A Coruña, Spain.

CHABERNEU RJ and BARRET ME (1998) Evaluation of methods for estimating stormwater pollutant loads. Water Environ. Res. 70 1295-1302.

CHEBBO G and GROMAIRE MC (2004) The experimental urban catchment 'Le Marais' in Paris: what lessons can be learned from it? J. Hydrol. 299 312-323. 
CRABTREE RW (1989) Sediments in sewers. J. Inst. Water and Environ. Manage. 3 569-578.

CRISTINA CM and SANSALONE JJ (2003) "First flush", power law and particle separation diagrams for urban storm-water suspended particulates. J. Environ. Eng.-ASCE 129 298-307.

CRISTINA CM, TRAMONTE J and SANSALONE JJ (2002) A granulometry-based selection methodology for separation of traffic-generated particles in urban highway snowmelt runoff. Water Air Soil Pollut. 136 33-53.

DELETIC A and MAKSIMOVIC C (1998) Evaluation of water quality factors in storm runoff from paved areas. J. Environ. Eng-ASCE 124 869-879.

ELLIS JB (1989) Urban Discharges and Receiving Water Quality. Pergamon Press, Oxford. 198 pp.

HEANEY JP, PITT R and FIELD R (2000) Innovative Urban WetWeather Flow Management Systems. Technomics Publishers, Lancaster. $535 \mathrm{pp}$.

METCALF and EDDY (1991) Wastewater Engineering: Treatment Disposal, and Reuse. McGraw-Hill Inc, Singapore. 1334 pp.

NOVOTNY V and OLEM H (1994) Water Quality: Prevention, Identification and Management of Diffuse Pollution. Van Nostrand Reinhold, New York. 1054 pp.

OTA JJ and NALLURI C (2003) Urban storm sewer design: approach in consideration of sediments. J. Hydraul. Eng.-ASCE 129 291-297.

SARTOR JD and BOYD GB (1972) Water Pollution Aspects of Street Surface Contaminants. US Environmental Protection Agency, Washington DC
STANDARD METHODS (1998) Standard Methods for the Examination of Water and Wastewater (20 ${ }^{\text {th }}$ edn.) APHA, AWWA and WPCF Washington DC.

SUÁREZ J and PUERTAS J (2005) Determination of COD, BOD and suspended solids during combined sewer overflow (CSO) events in some combined catchments in Spain. Ecol. Eng. 24 201-219.

SUÁREZ J, CAGIAO J, VÁZQUEZ F, DÍAZ-FIERROS F and PUERTAS J (2001) Quality aspects and behaviour of the pollutants in a separate catchment in the city of Santiago de Compostela. In: Brashear RW and Maksimovic C (eds.) Proc. ASCE-EWRI Int. Symp. Urban Drainage Modelling. 20-24 May 2001, Orlando, USA. 884-887.

SUTHERLAND RC and JELEN SL (2003) Stormwater quality modelling improvements needed for SWMM. In: James W (ed.) Practical Modelling of Urban Water Systems, 11. CHI, Ontario. 511 pp.

TAEBI A and DROSTE RL (2004) Pollution loads in urban runoff and sanitary wastewater. Sci. Total Environ. 327 175-184.

USEPA (1983) Results off Nationwide Urban Runoff Program, Volume 1. Final Report. US Environmental Protection Agency (USEPA), Washington DC.

USEPA (1986) Methodology for Analysis of Detention Basins for Control of Urban Runoff Quality. Environmental Protection Agency (EPA), Washington DC.

USEPA (2004) Storm Best Management Practices Design Guide. Volume 3: Basin Best Management Practices. Environmental Protection Agency (EPA), Cincinnati. 108 pp. 